\title{
Study on Application of Mathematical History in Mathematics Textbooks in Mainland China
}

\author{
Jian Wang, Zezhong Yang* \\ School of mathematics science, Shandong Normal University, Jinan, China \\ School of mathematics science, Shandong Normal University, Jinan, China \\ Email:zhongzee@163.com
}

Keywords: Mathematical history; Mathematics textbooks; Mathematics teaching; Application

\begin{abstract}
This paper focuses on the studies about the application of mathematical history in mathematics textbooks in mainland China. It mainly summarizes the studies about the application of mathematical history in mathematics textbooks and in mathematics teaching, and appraises these studies and puts forward some suggestions for further research.
\end{abstract}

\section{Introduction}

Mathematical history plays an important role in mathematics education. Chinese mathematics educators attach great importance to the application of Mathematical history in mathematics education. They discussed it as early as in 1920s. Recently, with the reform of mathematics education in mainland China and the rise of international HPM activities, the studies on application of Mathematical history in mathematics education in mainland China become more and more abundant. In these studies, there are many aspects involved, for example the value of history of mathematics in mathematics education and the role it plays, and which part of history of mathematics is suitable for mathematics education, etc. However the focus of these studies is on how to apply Mathematical history in mathematics textbooks, since the mathematics textbooks are considered as the main and important platform to let students know mathematics knowledge and Mathematical history in mainland China. This paper is to summarize these studies.

\section{The principles about the selection of mathematical history}

When we write the mathematical history into mathematics textbooks, the first consideration is how to select it among the vast amount of historical facts.

Concerning this question, there are many studies at present, in which the most famous view is given by Li Mingzhen and Pang Kun. They think we should insist on five principles. They are the principles of scientific verdict, of matching and coordination, of functional complex, of diverse space-time and of readability and interestingness. The principle of scientific verdict means that the knowledge of mathematical history written in mathematics textbooks must be true and objective. The principle of matching and coordination means that the knowledge of mathematical history must be closely linked to the content of mathematics. The principle of functional complex means that the knowledge of mathematical history should have diversiform educational functions. The principle of diverse space-time means that the knowledge of mathematical history must be various and can reflect 
mathematical history of different periods, different countries, different nationalities and different cultural backgrounds. The principle of readability and interestingness means that the history must be readable and interesting to students[1].

The following view is given by Li Hongting. She thinks that the principles about choosing historical materials should include the purpose and adaptability principles, education and authenticity principles, relevance and timeliness principles, flexibility and diversity principles. The purpose and adaptability principles mean that the historical materials used should have educational purposes and fit for the cognitive abilities of students. The education and authenticity principles and relevance and timeliness principles mean that the historical materials included should be combined with the specific content of mathematics, and can effectively advance the education and learning of mathematics, and must be authentic at the same time[2].

In addition, Zhu Liang also thinks that we should adhere to three principles while choosing the historical facts. They are the principle of complementary advantages, the principle of process and results, and the principle of being in accordance with the rule of cognition of students. The principle of complementary advantages means that the historical material used and the knowledge of mathematics should complement each other, and can promote the mathematics learning. The principle of process and results means that the history material used should focus on description of the origin and the development of mathematical knowledge. The principle of being in accordance to the cognition rule of students means that the history material used should be easily readable, and completely understood[3].

Also, Liu Chao thinks that the knowledge of mathematical history must be authentic and objective, and be closely linked to the teaching content of mathematics at school. It must have long-lasting values, and can reflect the mathematics history of different periods, different ethnic and cultural backgrounds. Meanwhile, it must be interesting[4].

Also, Liu Ling and Xu Wenbin think that when we choose the material of mathematical history we must pay attention to the cultural side and various topics in the mathematical history[5].

It can be seen that concerning the principles of the selection of the knowledge of mathematical history, the Chinese mathematics educators are inclined to that it must be of high certainty, can complement the knowledge of mathematics in textbooks, can improve the quality of mathematics education, and it must be interesting as well. It shows that the Chinese mathematics educators are clearly conscious of the purpose of the application of mathematical history in mathematics education, and the direction of their studies is basically right on the whole.

\section{The method of adding the mathematical history into mathematics textbooks}

After the discussion of what kind of knowledge of mathematical history should be selected, the next is how to add it into the mathematics textbook.

Li Mingzhen and Pang Kun gave four methods as follow: adding mathematics history into every part of mathematics textbooks, adding reading materials, setting up "Mathematical history election talk" special topic and recommending mathematics history books to the students. The first method means to decompose the mathematical history knowledge, and add them into mathematics textbooks according to the requirement of the preplanned content and teaching circumstances. Adding reading materials is to insert some readable mathematical history materials into every chapter of the textbooks[1]. 
Liu Chao holds the same ideas, yet he thinks we should attach importance to mathematical history which includes important mathematics thoughts, put the inspiring parts into mathematics textbooks, and introduce different opinion about the same questions. At the same time we should introduce it in diverse ways, such as pictures, graphics and so on[4]. Meanwhile, Zhu Liang suggests three methods as follow: introduce the history of different branches, introduce the mathematical history concepts, and introduce the history of development and solutions of the famous mathematics problems [3]. In addition Liu Ling and $\mathrm{Xu}$ Wenbin think it should be done in diversified ways and the spiral ascending way is the best way[5].

It seems that Chinese mathematics educators haven't reached a consensus on the employment of adding mathematical history into textbooks. But yet we can find in general that they are not incompatible, their studies differentiate as they have different focus more or less on the aspects involved. In these studies, there are also some same views, such as the view of adding mathematical history knowledge into every part of the textbooks and the view of adding reading materials of mathematical history into the mathematics textbook.

\section{The practical studies of adding history of mathematics into mathematics textbooks}

In Concern of the studies about adding mathematical history into the mathematics textbook, besides many theoretical studies, there are lots of practical studies and explorations also.

In the practice of adding mathematical history into mathematics textbooks, the most common method is to insert mathematical history as reading materials based on the preplanned content and the teaching circumstances, for instance insert the reading materials about equation development in the equation chapter, and insert additional geometry history in geometry textbook. It is called the way of mathematics knowledge eliciting mathematical history[6]. Almost all the knowledge of mathematical history in mathematics textbooks published by People's Education Press is presented in this way currently.

In addition, there is another way to add mathematical history into textbooks. It is the way of mathematical problems eliciting history of mathematics. That is to say, we list a mathematics problem at first, and then introduce the related mathematical history. A good example of the way used was given by the introduction of Goldbach conjecture in the mathematics textbook for primary school which was published in 2006 by People's press[7].

The mathematical history added in current textbooks generally can be divided into the following four categories: (1) The anecdotes of mathematicians, such as the story of Yang Hui, the story of Hua Luogeng; (2) The story of mathematics problem solved by famous mathematicians, such as the story of solving the Goldbach conjecture by Chen Jingrun; (3) Some relevant mathematics historical data, such as the origin of sign multiplication, the invention of decimal;(4) The famous mathematics historic problems, such as the problem of "Ji tu tong long"(The problem of chickens and rabbits in the same cage[8]) and Goldbach conjecture.

The most common method about the description of mathematical history in current mathematics textbooks is to process it firstly according to the cognitive characteristics of students so that it can suit the learning habits of students, for example simplifying the stories of mathematical history, using the manner and language that students like, and presenting it with pictures or graphics. This method can be divided into two specific approaches. The first is the Language-based approach supplemented by pictures or diagrams, and the other is the picture or diagram-based approach supplemented by language. 
The Language-based approach is usually adopted in high-grade mathematics textbooks[9,10]; contrarily the picture or diagram-based approach is usually used in low-grade mathematics textbooks. For example, the introduction of the origin of Arabic numerals in fourth-grade elementary school mathematics textbooks published by the People's Education Press in 2009 just adopts the latter approach. When the authors introduce it, they just use four simple sentences, and the main content is four colorful pictures[11].

The mathematical history introduced in present mathematics textbooks comes from both foreign mathematical history and Chinese history of mathematics, while in quantity the foreign mathematical history is more than Chinese mathematical history. But the Chinese mathematical history also accounts for a considerable proportion. For example, in the mathematics textbooks published by the People's Education Press, the knowledge of Chinese mathematical history occupies almost half of the entire content of mathematical history.

The Chinese mathematicians involved in Chinese mathematical history in present textbooks not only include ancient mathematicians, such as Liu Hui, Zu Chongzhi, Zu Geng, Jia Xian, Yang Hui and Qin Jiushao, but also include some modern mathematicians, such as Li Shanlan, Hua Luogeng, Chen Xingshen and Chen Jingrun. The knowledge of Chinese mathematical history involved not only include pure ancient mathematics knowledge, such as the method of Chinese ancient count, count chips, Chinese ancient equation, Gougu theorem (the Chinese version of Pythagoras's theorem), but also include some knowledge of ancient mathematics games, such as the third-order magic square and jigsaw puzzle. So it fully reflected the respect for Chinese ancient mathematics.

These shows that Chinese mathematics educators have fully considered the influence of mathematical history to mathematics education, the combination of history of mathematics and mathematics, and the cognitive characteristics and students' interestingness. In addition, they have considered the moral effect of history of mathematics to students. So their method of applying mathematical history into textbooks is basically scientific.

\section{Rethinking}

From above studies, we can see Chinese mathematics educators have discussed the application of mathematical history in mathematics textbooks Widely and profoundly, and have obtained quit a lot of meaningful results, especially in aspect of practice of adding mathematical history into textbooks. However some shortcomings still exist, such as (1) the content of mathematical history in current mathematics textbook is insufficient. Much valuable knowledge of mathematical history hasn't appeared in the textbooks yet; (2) when the mathematical history is introduced, although the combination of mathematical history and mathematical knowledge was noticed, what we have done is not enough. Perhaps it is for this reason, the effect of mathematical history to mathematics education has not been obvious by now; (3) the ways of adding mathematical history into textbooks obviously is inadequate, so some researchers suggest more ways be adopted to do it[6]; (4) the method to introduce mathematical history in mathematics textbooks at present mainly is to provide reading materials, so the method is obviously very simple; (5) the formal teaching experimental study about the application textbooks in mathematics teaching which included history of mathematics hasn't appeared, so we do not know whether it can really promote the mathematics teaching and what is the real effect. So Chinese educators should start wider and deeper studies. 


\section{References}

[1]Li M. Z. \&Pang K., The principles, modes and questions about the mathematics history's integrating into mathematics books. Bulletin des Sciences Mathematics, 45(3) (2006) 23-25.

[2]Li H. T., The new view of curriculum reform: the history of mathematics goes into the new mathematics curriculum. Curriculum, Teaching Material, And Method, 25(9) (2005)51-54.

[3]Zhu. L., The theory and practice of integrating history of mathematics to mathematics teaching in high school (Unpublished doctoral dissertation).Shanhai normal university, Shanhai, (2008).

[4]Liu C., Study on the integration of mathematical history and Mathematics Education (Unpublished master dissertation).Qufu normal university, Qufu, (2007).

[5]Li L. \& Xu W. B., Analysis of and suggestions on the contents concerning mathematics history in the primary mathematics textbook. Journal of Tianjin Normal University (Elementary education edition), 9(2) (2008) 43-46.

[6]Yang Y. H., The analyzing of the content and arranging method about the mathematics history in primary school mathematics textbooks. Journal of Mathematic Education, 16(4) (2007) 55-59.

[7]Group of primary school mathematics editors, Mathematics textbook 2(For fifth-grade), Beijing, People's press, 2006, pp.17.

[8]Group of primary school mathematics editors, Mathematics textbook 1(For sixth-grade), Beijing, People's press, 2012, pp.112.

[9] Group of middle school mathematics editors, Mathematics textbook 2(For Eighth-grade), Beijing, People's press, 2012, pp.16,35.

[10] Group of middle school mathematics editors, Mathematics textbook 2(For Ninth-grade), Beijing, People's press, 2012, pp.83.

[11]Group of primary school mathematics editors, Mathematics textbook1(For fourth-grade), Beijing, People's press, 2009, pp.17. 